\title{
Influence of Telmisartan on Pharmacodynamic and Pharmacokinetic Properties of Glimepiride- metformin Combination Using Rodent and Non-Rodent Models
}

\author{
Beere Nagaraju*, Anilkumar KV \\ Department of Pharmacology, Visveswarapura Institute of Pharmaceutical Sciences, Bengaluru, Karnataka, INDIA.
}

\begin{abstract}
Aim: The present study was planned to evaluate the pharmacodynamic and pharmacokinetic interactions between telmisartan and glimepiride + metformin in single and multiple dose studies using rats and rabbits. Materials and Methods: The blood samples were collected from the rats/ rabbits from retro orbital/ marginal ear vein respectively. The serum glucose, plasma insulin and serum glimepiride were estimated at respective time intervals in all treatment groups. Results: The single and multiple dose treatments of telmisartan alone and combined treatment with glimiperide + metformin does not showed any significant reduction of glucose and elevated insulin levels in normal and diabetic rats and showed synergistic hypoglycemic activity by enhancing blood glucose reduction and peak insulin levels in normal rabbits. The serum glimepiride levels were found to be enhanced with telmisartan single and multiple dose treatments. There is significant increase in the pharmacokinetic parameters of glimepiride like $\mathrm{AUC}_{0-\infty}$, $\mathrm{AUMC}_{0-\mathrm{t}^{\prime}} \mathrm{AUMC}_{0-\infty}, \mathrm{t}_{1 / 2}, \mathrm{C}_{\max }$ and MRT and there is a decrease in clearance $(\mathrm{Cl})$ with single and multiple dose treatments of telmisartan. Conclusion: The interactions observed in rabbits (a non rodent model) but not in rats (a rodent model). Hence care must be taken while prescribing telmisartan in combination with glimipiride-metformin.
\end{abstract}

Key words: Telmisartan, Glimepiride, Metformin, Pharmacokinetics, Pharmacodynamics.

\section{INTRODUCTION}

The emerged risk factor for the mortality and morbidity of diabetes is raised in blood pressure. According to the Global Burden of Disease (GBD) 2017, higher levels of systolic blood pressure was observed globally as risk factor with mortality rate of 10.2 million and 208 million people are suffering with disabilities. ${ }^{1}$ The age dependent hypertension was observed more in men $(24.5 \%)$ than women $(20 \%)$. The persistent hypertension cause increase in severity up to 7.2 fold and 37 fold increase in chances of mortality in diabetic patients. ${ }^{2}$ The reduced systolic blood pressure upto $10 \mathrm{~mm}$ of $\mathrm{Hg}$ may control the occurrence of diabetes and related complications upto
27\%, 11\% myocardial infarction and 13\% of microvascular complications. ${ }^{3}$

In general, hypertension is not associated with DM1, but the DM2 is associated with hypertension even at time of diagnosis. ${ }^{4}$ The incidence of essential hypertension is associated with degree of obesity, elderly age and cardiovascular risk. ${ }^{5}$ The mechanism of renin angiotensin aldosterone system and vascular sensitivity are also played a key role in essential hypertension. ${ }^{6}$ The hyperinsulinemia and insulin sensitivity are the leading cause of diabetes associated hypertension, because insulin promotes the sodium retention and activity of sympathetic system. ${ }^{7}$ Such conditions were controlled with recommended combined
Submission Date: 26-08-2020; Revision Date: 09-08-2021; Accepted Date: 10-09-2021

DOI: 10.5530/ijper.55.4.206 Correspondence: Dr. Beere Nagaraju, Department of Pharmacology, Visveswarapura Institute of Pharmaceutical Sciences, Bengaluru-560070, Karnataka, INDIA.

Phone: +91 9341228168, Email-dr.bnr2011@gmail. com

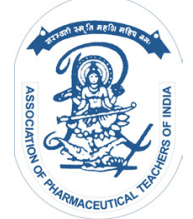

www.ijper.org 
drug therapies. The standard care of type 2 diabetes includes aspirin, antihypertensive agent and anticholesteremic agents according to the American Diabetes Association (ADS) 2015. An increasing number of simultaneous medications increase the risk of a patient experiencing adverse drug reactions or drug interactions with diabetics. ${ }^{9}$

Polypharmacy is a place of concern for the elderly for a number of reasons. Older people are at greater risk of developing harmful effects due to the physical changes and weight loss associated with aging; this risk is greatly increased due to the repeated drug administration of multiple medications for the concomitant disease. ${ }^{10}$ The chances of drug-drug interactions are found to be more in the practice of polypharmacy. Hence, it needs to identify the potential drug-drug interaction studies in patients in multidrug use. ${ }^{11}$ Several epidemiological studies indicating that the use of renin angiotensin system blockers (ARB's) was found to more and efficient in type 2 diabetics. ${ }^{12}$ Based on the need, the current study was designed to evaluate the influence of widely prescribing $\mathrm{ARB}$, telmisartan on pharmacodynamic and pharmacokinetic aspects of commonly prescribed combination of Glimepiride (Glim) with Metformin (Met) using rodent and non rodent models.

\section{MATERIALS AND METHODS}

\section{Drugs and Chemicals}

APIs were provided as gift samples by Apotex Research Pvt Ltd., Bangalore for the purpose of evaluation in our research work. All chemicals used were of analytical grade.

\section{Experimental Animals}

Albino rats and rabbits procured from Sri. Venkateswara Enterprises, Bangalore, India were used in the study. They were maintained under standard laboratory conditions at ambient temperature of $25 \pm 2^{\circ} \mathrm{C}$ and $50 \pm 15 \%$ relative humidity with $12 \mathrm{~h}$ light $/ 12 \mathrm{~h}$ dark cycle. They were provided with a standard pellet diet (Hindustan Lever Ltd., Bangalore, India) and water ad libitum. All animal procedures have been approved by the Institutional Animal Ethical Committee (No: VIPS/1442/15-16, Dated: 14.01.2016) in accordance with animal experimentation and care guidelines provided by IAEC/CPCSEA.

\section{Study in normal rats ${ }^{13,14}$}

A group of six albino rats weighing between $250-300 \mathrm{~g}$ were injected with glimepiride $(0.09 \mathrm{mg} / \mathrm{kg})+$ metformin (45 mg / kg) orally. The same group was given
$1.8 \mathrm{mg} / \mathrm{kg}$ body weight of oral telmisartan after a one-week washing period. The same group was also given $1.8 \mathrm{mg} / \mathrm{kg}$ body weight telmisartan $30 \mathrm{~min}$ before glimepiride $(0.09 \mathrm{mg} / \mathrm{kg})+$ metformin $(45 \mathrm{mg} / \mathrm{kg})$, after a continuous wash period of 1 week. Blood samples were withdrawn from retro orbital plexus at $0,1,2,4,6$, $8,10,12,14$ and $16 \mathrm{~h}$ intervals.

\section{Study in diabetic rats ${ }^{15-17}$}

Diabetes is caused by administration of alloxan monohydrate in two doses $100 \mathrm{mg}$ and $50 \mathrm{mg} / \mathrm{kg}$ intraperitoneal body weight for two days in a row. A group of 6 rats with a blood glucose level above $250 \mathrm{mg} / \mathrm{dL}$ was selected from the study. The study was similar to that of normal rats repeated in a diabetic group. ${ }^{13,14}$

\section{Study in normal rabbits ${ }^{14}$}

A group of albino rabbits weighing between 1.38 to $1.7 \mathrm{~kg}$ was given Glimepiride + Metformin $(0.07 \mathrm{mg}+35$ $\mathrm{mg} / 1.5 \mathrm{~kg}$ ) orally. The same group was given $1.4 \mathrm{mg} / 1.5 \mathrm{~kg}$ of telmisartan in a single treatment and in multiple doses. In addition to all medical procedures blood samples are collected through marginal ear vein. Blood samples were collected at 0 (predose), 1, 2, 3, 4, 6, 8, 12, 18 and $24 \mathrm{~h}$ after drug administration. Blood samples are collected in clean centrifuge tubes.

Blood samples were analyzed for blood glucose by using GOD/POD method, ${ }^{18}$ Insulin by using Chemiluminescence assay ${ }^{19}$ and estimation of serum Glimepiride by using HPLC method. ${ }^{20,21}$

\section{Data and Statistical Analysis}

Results were represented using mean and standard error mean. Two way ANOVA, Bonferroni post test was used to give significance.

\section{RESULTS AND DISCUSSION}

Since high blood pressure is often associated with insulin resistance and glucose tolerance disorders, the metabolic effect of anti-hypertensive agents is considered an important consideration for first-line treatment options. The chances of combining antidiabetic and antihypertensive treatments are metformin and glimiperide with ARBs because, in diabetic hypertensives, ACEIs are the first line drugs in high blood pressure management, and can be replaced by ARBs if patients are intolerant. Recent research suggests that ARBs should be equal to ACEI in reducing both complex hypertension and diabetic complications. ${ }^{11}$

The commonly prescribed ARBs in diabetic hypertension are losartan, candesartan, irbesartan, olmesartan and telmisartan. Among these ARBs, Telmisartan shown to 
have normoglycemic activity by reducing fasting glucose and insulin levels and improvement in homeostatic model assessment. ${ }^{23,24}$ It is reported that there is a possibility of pharmacodynamic drug interaction between telmisartan with antidiabetic agents such as metformin and glimiperide. ${ }^{25}$

Hence, the study was to evaluate the pharmacodynamic and pharmacokinetic influence of telmisartan on combination of glimepiride + metformin using rodent and non rodent models to represent healthy and diabetic status.

In normal rats, glimepiride $(0.09 \mathrm{mg} / \mathrm{kg})+$ metformin $(45 \mathrm{mg} / \mathrm{kg}$ ) alone showed 36.89\% blood glucose reduction at $4 \mathrm{~h}$. Telmisartan at a dose of $1.8 \mathrm{mg} / \mathrm{kg}$ body weight found to have $12.82 \%$ reduction in blood glucose levels at $2 \mathrm{~h}$. In combination, telmisartan does not influence the hypoglycemic activity produced by glimepiride + metformin with single dose $36.03 \%$ and multiple dose $36.67 \%$ treatments (Figure 1). The insulin levels at peak reduction in blood glucose levels were also found to be not altered with single and multiple dose treatments at $4 \mathrm{~h}$ significantly (Table 1 ). During single drug administration of Telmisartan did not produce hypoglycemia and even in not influence the blood levels of glimepiride + metformin both in single and multiple dose treatments indicates there is no existence of interaction. In diabetic rats, glimepiride $(0.09 \mathrm{mg} / \mathrm{kg})+$ metformin $(45 \mathrm{mg} / \mathrm{kg}$ ) showed $41.96 \%$ blood glucose reduction at $4 \mathrm{~h}$ and telmisartan at $1.8 \mathrm{mg} / \mathrm{kg}$ does showed $17.44 \%$ blood glucose reduction at $2 \mathrm{~h}$. In combination, the selected dose of telmisartan does not influence the antihyperglycemic activity produced by glimepiride + metformin with single dose $41.69 \%$ and multiple dose

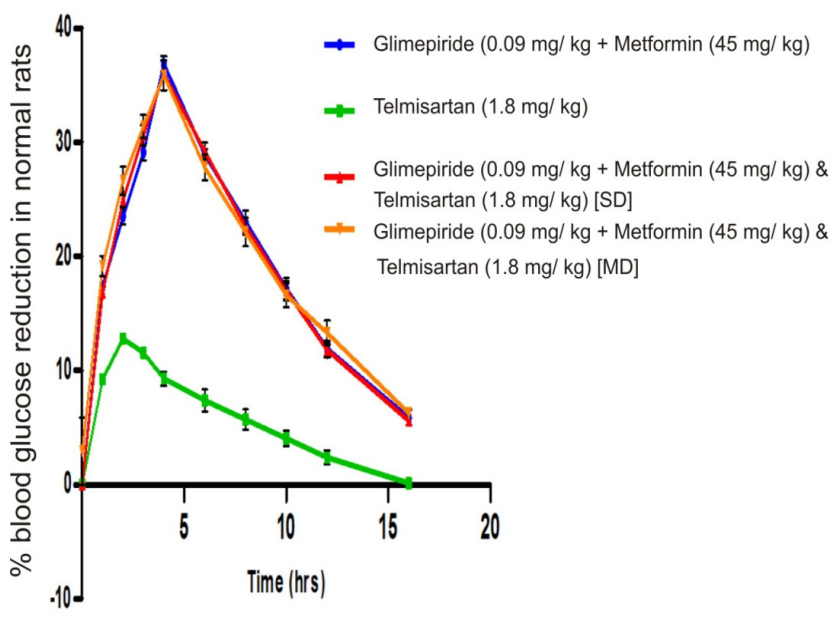

Figure 1: Average percent blood glucose reduction after administration of glimepiride + metformin, telmisartan and in combination in single and multiple dose treatement in normal rats.

\section{Table 1: Mean Serum insulin ( $\mu \mathrm{IU} / \mathrm{mL})$ with mean}

serum glucose level $(\mathrm{mg} / \mathrm{dL})$ in Glim+Met,

Telmisartan and single and multiple dose treatment

Glim +Met+Telmisartan in normal rats.

\begin{tabular}{|c|c|c|c|}
\hline Groups & Time (hrs) & $\begin{array}{l}\text { Mean serum } \\
\text { glucose levels } \\
\text { (mg/dL) }\end{array}$ & $\begin{array}{l}\text { Serum Insulin } \\
\quad(\mu \mathrm{IU} / \mathrm{mL})\end{array}$ \\
\hline \multirow{2}{*}{ Glimepiride } & 0.00 & $79.50 \pm 0.84$ & $9.97 \pm 0.28$ \\
\hline & 4.00 & $50.17 \pm 0.66$ & $10.45 \pm 0.17$ \\
\hline Telmisartan & 2.00 & $69.83 \pm 2.07$ & $9.91 \pm 0.30$ \\
\hline $\begin{array}{c}\text { Glimepiride + } \\
\text { Telmisartan } \\
\text { (SD) }\end{array}$ & 4.00 & $55.00 \pm 0.69$ & $10.06 \pm 0.14$ \\
\hline $\begin{array}{c}\text { Glimepiride + } \\
\text { Telmisartan } \\
\text { (MD) }\end{array}$ & 4.00 & $55.17 \pm 1.68$ & $10.12 \pm 0.18$ \\
\hline
\end{tabular}

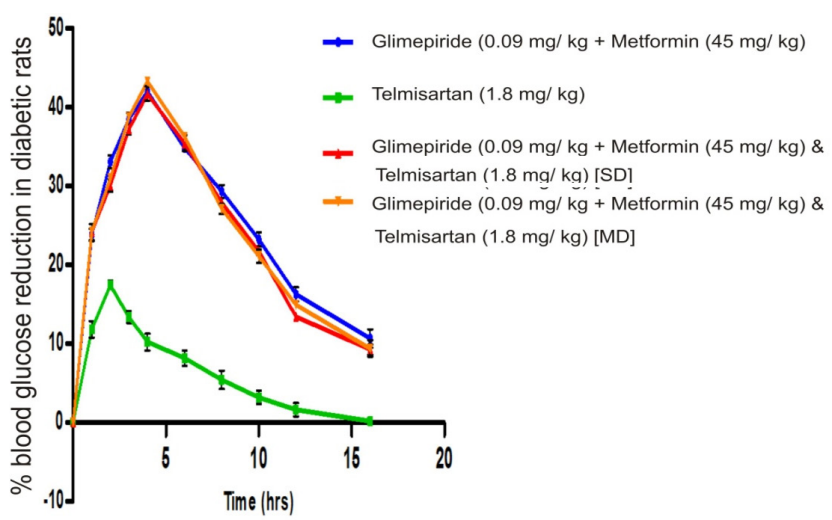

Figure 2: Average percent blood glucose reduction after administration of glimepiride + metformin, telmisartan and in combination in single and multiple dose treatement in diabetic rats.

\section{Table 2: Mean Serum insulin ( $\mu \mathrm{lU} / \mathrm{mL})$ with mean} serum glucose level $(\mathrm{mg} / \mathrm{dL})$ in Glim+Met,

Telmisartan and single and multiple dose treatment Glim +Met+Telmisartan in diabetic rats.

\begin{tabular}{|c|c|c|c|}
\hline Groups & Time (hrs) & $\begin{array}{c}\text { Mean serum } \\
\text { glucose } \\
\text { levels }(\mathbf{m g} / \mathbf{d L})\end{array}$ & $\begin{array}{c}\text { Serum } \\
\text { Insulin }(\boldsymbol{\mu l \mathrm { IU } /} \\
\mathbf{m L})\end{array}$ \\
\hline Glimepiride & 0.00 & $259.50 \pm 5.58$ & $8.03 \pm 0.18$ \\
\cline { 2 - 4 } & 4.00 & $150.50 \pm 2.62$ & $10.41 \pm 0.31$ \\
\hline Telmisartan & 2.00 & $208.50 \pm 7.25$ & $9.02 \pm 0.17$ \\
\hline $\begin{array}{c}\text { Glimepiride+ } \\
\text { Telmisartan (SD) }\end{array}$ & 4.00 & $152.50 \pm 4.65$ & $10.17 \pm 0.17$ \\
\hline $\begin{array}{c}\text { Glimepiride + } \\
\text { Telmisartan (MD) }\end{array}$ & 4.00 & $146.50 \pm 3.38$ & $10.53 \pm 0.22$ \\
\hline
\end{tabular}

43.26\% treatments (Figure 2). The insulin levels were not found to be enhanced at peak reduction of blood glucose with glimepiride + metformin at $4 \mathrm{~h}$ compared to $0 \mathrm{~h}$ (Table 2). This indicates there is no existence of 
pharmacodynamic interaction between telmisartan and glimepiride + metformin in diabetic rats.

In normal rabbits, glimepiride $(0.07 \mathrm{mg} / 1.5 \mathrm{~kg})+$ metformin $(35 \mathrm{mg} / 1.5 \mathrm{~kg})$ showed $35.51 \%$ blood glucose reduction at $4 \mathrm{~h}$. The selected dose of telmisartan at $1.4 \mathrm{mg} / 1.5 \mathrm{~kg}$ showed $42.30 \%$ blood glucose reduction at $4 \mathrm{~h}$. Telmisartan found to produce significant enhancement of hypoglycemic activity of glimepiride + metformin with single $42.30 \%$ and multiple dose $43.25 \%$ treatments (Figure 3). The insulin levels of glimepiride + metformin were found to be elevated at $4 \mathrm{~h}$ compared to that of $0 \mathrm{~h}$ (Table 3). The telmisartan in single and multiple dose treatments enhanced the

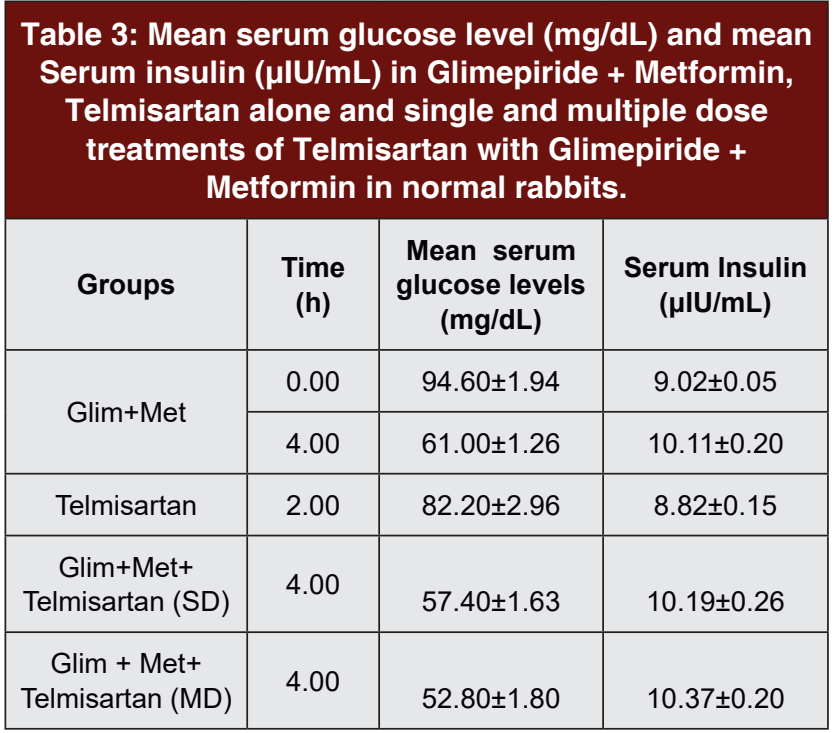

hypoglycemic activity in rabbits. The serum insulin levels were found to be enhanced with single dose and multiple dose treatments of telmisartan respective to the blood glucose levels. The serum glimepiride levels were found to be enhanced significantly with single and multiple dose treatments of telmisartan from $1 \mathrm{~h}$ to $24 \mathrm{~h}$ at peak level at $4 \mathrm{~h}$ (Figure 4). There is significant increase in the pharmacokinetic parameters of glimepiride like $\mathrm{AUMC}_{0-\mathrm{t}}, \mathrm{AUMC}_{0-\infty}$, and MRT and there is decrease in clearance $(\mathrm{Cl})$ with single and multiple dose treatment of telmisartan. The enhancement in the serum glimepiride levels and pharmacokinetic parameters indicate that there is a pharmacokinetic interaction between telmisartan and glimepiride.

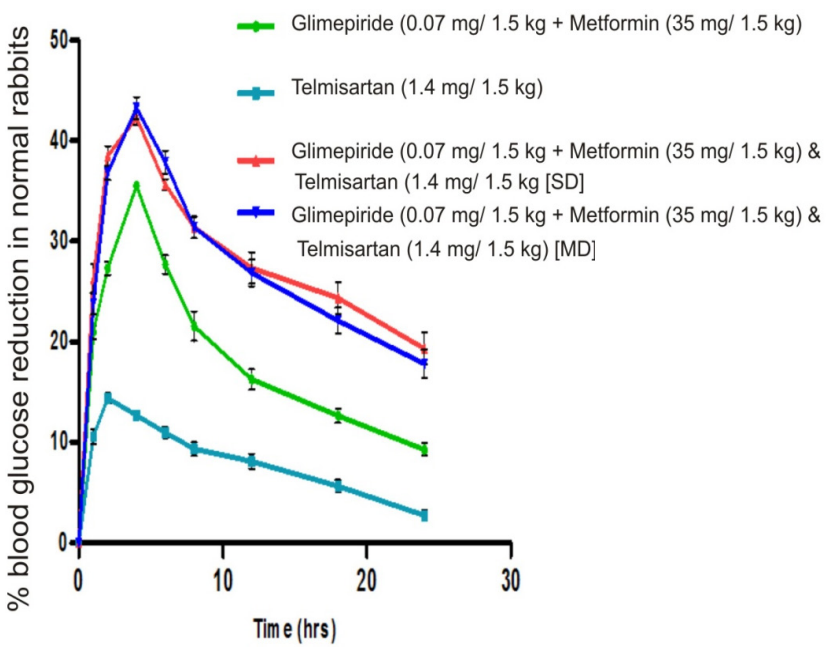

Figure 3: Average percent blood glucose reduction after administration of glimepiride + metformin, telmisartan and in combination in single and multiple dose treatement in normal rabbits.

\begin{tabular}{|c|c|c|c|}
\hline \multirow{2}{*}{$\begin{array}{l}\text { Pharmacokinetic } \\
\text { parameter }\end{array}$} & \multicolumn{3}{|c|}{ Mean Pharmacokinetic Parameters (Mean \pm SEM) } \\
\hline & Glimepiride alone & Glimepiride + Telmisartan (SD) & Glimepiride + Telmisartan (MD) \\
\hline$A \cup C_{0-24}(\mu \mathrm{g} / \mathrm{ml} / \mathrm{h})$ & $133.62 \pm 4.19$ & $151.46 \pm 1.65^{\star}$ & $152.65 \pm 4.66^{*}$ \\
\hline$A \cup C_{0-\alpha}(\mu \mathrm{g} / \mathrm{ml} / \mathrm{h})$ & $143.56 \pm 5.63$ & $165.92 \pm 2.65^{*}$ & $168.63 \pm 6.87^{*}$ \\
\hline $\operatorname{AUMC}_{0-24}\left(\mu \mathrm{g} / \mathrm{ml} / \mathrm{h}^{*} \mathrm{~h}\right)$ & $1094.19 \pm 84.75$ & $1351.27 \pm 68.25^{*}$ & $1421.82 \pm 79.76^{*}$ \\
\hline $\operatorname{AUMC}_{0-\alpha}\left(\mu \mathrm{g} / \mathrm{ml} / \mathrm{h}^{*} \mathrm{~h}\right)$ & $1423.25 \pm 138.59$ & $1844.93 \pm 156.08^{*}$ & $1971.36 \pm 171.35^{*}$ \\
\hline $\mathrm{Ka}\left(\mathrm{h}^{-1}\right)$ & $1.15 \pm 0.00$ & $1.15 \pm 0.00^{\mathrm{ns}}$ & $1.15 \pm 0.00^{\mathrm{ns}}$ \\
\hline$T_{1 / 2}(h)$ & $6.14 \pm 0.27$ & $6.78 \pm 0.38^{\mathrm{ns}}$ & $7.02 \pm 0.29^{\mathrm{ns}}$ \\
\hline$V d_{s s}(m \mathrm{l} / \mathrm{kg})$ & $1451.49 \pm 43.66$ & $1432.68 \pm 97.59^{\mathrm{ns}}$ & $1486.23 \pm 46.02^{\text {ns }}$ \\
\hline $\mathrm{Cl}(\mathrm{ml} / \mathrm{h} / \mathrm{kg})$ & $163.52 \pm 6.31$ & $140.77 \pm 2.23^{*}$ & $139.27 \pm 5.50^{*}$ \\
\hline $\operatorname{Tmax}(\mathrm{h})$ & $4.00 \pm 0.00$ & $4.00 \pm 0.00^{\mathrm{ns}}$ & $4.00 \pm 0.00^{\mathrm{ns}}$ \\
\hline Cmax $(\mu \mathrm{g} / \mathrm{ml})$ & $12.29 \pm 0.25$ & $13.08 \pm 0.35^{\mathrm{ns}}$ & $12.63 \pm 0.22^{\mathrm{ns}}$ \\
\hline MRT (h) & $9.83 \pm 0.58$ & $11.08 \pm 0.80$ * & $11.61 \pm 0.58^{*}$ \\
\hline
\end{tabular}

$p>0.05^{\text {ns, }} p<0.05^{*}$ Significance followed by unpaired t-test 


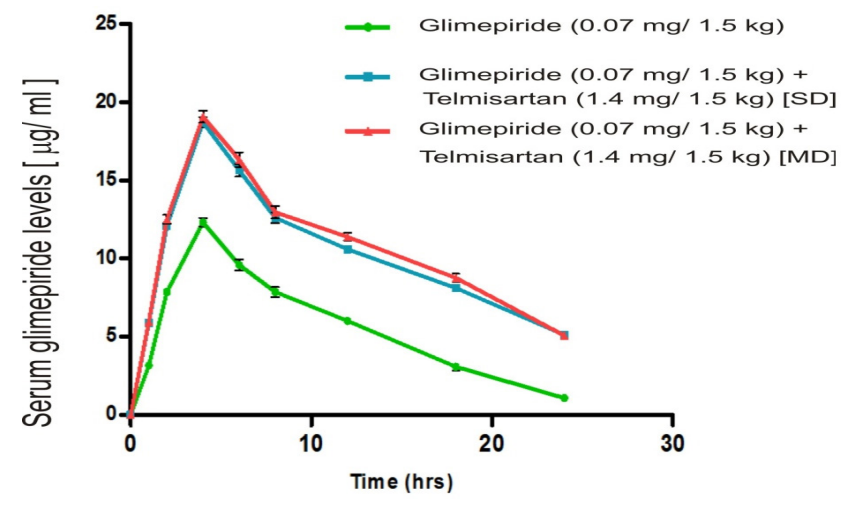

Figure 4: Serum glimepride levels $(\mu \mathrm{g} / \mathrm{ml})$ alone and glimepiride with telmisartan in single and multiple dose treatment in normal rabbits.

The observed pharmacokinetic interactions in rabbits might be due to displacement of glimepiride from the protein binding sites by telmisartan as both the drugs are highly protein bound in nature. ${ }^{26}$ Such interactions are not observed in rats. The present study concludes that the interactions observed in rabbits (a non rodent model) but not in rats (a rodent model). Hence care must be taken while prescribing telmisartan in combination with glimepiride-metformin.

\section{ACKNOWLEDGEMENT}

The authors wish to thank Dr M Ravindran, Chief Medical Superintendent, South Western Railway, Bangalore Division; Dr. G Y Narmada, Principal and Dr. Meera Sumanth, Professor and Head, Department of Pharmacology, Visveswarapura Institute of Pharmaceutical Sciences, Bangalore and Apotex Research Pvt Ltd., Bangalore for their kind cooperation in sparing the employee (author") on leave/permission for pursuing higher studies; extending their cordial support to conduct present study and providing a free samples of APIs for the purpose of evaluation in our research work respectively.

\section{CONFLICT OF INTEREST}

The authors declare no conflict of interest.

\section{ABBREVIATIONS}

AUC $_{0-\infty}$ : Area under the concentration time-curves from time zero to infinity; $\mathbf{A U M C}_{0-\mathrm{t}}$ : Area under the concentration-time curve from time zero to the last measurable concentration using linear-log. trapezoidal rule; $\mathbf{A U M C}_{0-\infty}$ : Area under first moment curve; $\mathbf{t}_{1 / 2}$ : Pharmacokinetic term half-life; $\mathbf{C}_{\max }$ : Maximum (or peak) of serum concentration; MRT: Mean residence time; Cl: Clearance; DM1: Diabetes Mellitus Type 1; DM2: Diabetes Mellitus Type 2; APIs: Active Pharmaceutical Ingredients; VIPS: Visveswarapura Institute of Pharmaceutical Sciences; IAEC: Institutional Animal Ethics Committee; CPCSEA: Committee for the Purpose of Control and Supervision of Experiments on Animals; Mg: Milligram; Kg: Kilogram; H: Hour; dL: Decilitre; GOD/POD: Glucose oxidase-peroxidase; ELISA: Enzyme-linked immunosorbent assay; HPLC: High performance liquid chromatography; ANOVA: Analysis of variance; ACEIs: Angiotensin-converting enzyme inhibitors; SD: Single dose; MD: Multiple dose; ml: Milli litre; $\mu \mathrm{IU}$ : Milli-international units; SEM: Standard error of measurement; ${ }^{\circ} \mathrm{C}$ : Degree Centigrade; $\mu \mathrm{g}$ : Microgram; $\mu \mathrm{m}$ : Micrometer; Ka: Absorption rate constant; Vdss: volumes of distribution are commonly calculated by the steady-state; $\mathbf{C}_{\max }$ : Maximum concentration; $\mathbf{T}_{\max }$ : Time at which the Cmax.

\section{REFERENCES}

1. Institute for Health Metrics and Evaluation (IHME). Findings from the global burden of disease Study 2017. Seattle: IHME; 2018.

2. Ganesh J, Viswanathan V. Management of diabetic hypertensives. Indian J Endocrinol Metab. 2011 Oct;15;Suppl 4:S374-9. doi: 10.4103/22308210.86982, PMID 22145142.

3. Tight blood pressure control and risk of macrovascular and microvascular complications in type 2 diabetes: UKPDS 38. UK Prospective Diabetes Study Group. BMJ. 1998;317(7160):703-13. doi: 10.1136/bmj.317.7160.703, PMID 9732337.

4. Lastra G, Syed S, Kurukulasuriya LR, Manrique C, Sowers JR. Type 2 diabetes mellitus and hypertension: an update. Endocrinol Metab Clin North Am. 2014 Mar;43(1):103-22. doi: 10.1016/j.ecl.2013.09.005, PMID 24582094.

5. Patan Fayaz PDS, Hiremath R, Nagaraju B, Anil Kumar KV, Eswarkumar K et al. Effectiveness of Cyperus rotundus in countering atherogenic diet induced changes in lipid profile and metabolism by normalising the plasma adiponectin concentration. Int J Phytopharmacol. 2017;8(4):143-58.

6. Jia G, Aroor AR, Hill MA, Sowers JR. Role of renin-angiotensinaldosterone system activation in promoting cardiovascular fibrosis and stiffness. Hypertension. 2018;72(3):537-48. doi: 10.1161/ HYPERTENSIONAHA.118.11065, PMID 29987104.

7. Zhou MS, Wang A, Yu H. Link between insulin resistance and hypertension: what is the evidence from evolutionary biology? Diabetol Metab Syndr. 2014;6(1):12. doi: 10.1186/1758-5996-6-12, PMID 24485020.

8. American Diabetes Association. Standards of medical care in Diabetes-2015 abridged for primary care providers. Clin Diabetes. 2015 Apr;33(2):97-111. doi: 10.2337/diaclin.33.2.97, PMID 25897193.

9. Nagaraju B, Anil Kumar KV, Ravindran M, Shekar HS, Anatha Naik Nagappa PGV. Multicenter study on prescribing practice of oral hypoglycemic agents in selected hospitals at Bangalore city. Eur J Pharm Med Research. 2016;3(2):210-13.

10. Nagaraju B, Padmavathi GV, Dattathreya G. Prevalence and Assessment of polypharmacy in Sri Devraj Urs Medical College and Hospital, Kolar. Int J Pharm Pharm Sci. 2012;4(1):488-93.

11. Murthy TEGK, Kommineni MK, Mayuren C. Influence of losartan on the hypoglycemic activity of glimepiride in normal and diabetic rats. Ther Adv Endocrinol Metab. 2013;4(5):133-38. doi: 10.1177/2042018813509397, PMID 24143270. 
12. Gopala Krishna Murthy TE, Mayuren C. Influence of irbesartan on the pharmacodynamics and pharmacokinetics of gliclazide in rats and rabbits. $J$ Preclin Clin Res. 2008;2(2):127-32

13. Swami AM, Shetty SR, Kumar SMS, Rao NV. A study on drug-drug interaction of Roxithromycin and anti-diabetic drugs. Indian Drugs. 2005;42(12):808-13.

14. Dhanabal SP, Kokate CK, Ramanathan M, Elango K, Kumar EP, Subbaraj T et al. Antihyperglycemic activity of polygala arvensis in alloxan diabetic rats. Indian Drugs. 2004;41(11):690-5

15. Mohan V, Mary Jelastin K, Tresina P. Antioxidant, antihyperlipidaemic and antidiabetic activity of Eugenia floccosa bedd leaves in alloxan induced diabetic rats. J Basic Clin Pharma. 2012;3(1):235-40. doi: 10.4103/09760105.103831

16. Trinder P. Determination of Glucose in Blood Using Glucose Oxidase with an Alternative Oxygen Acceptor. Ann Clin Biochem. 1969;6(1):24-7. doi: 10.1177/000456326900600108.

17. Finlay JWA, Dillard RF. Appropriate calibration curve fitting in ligand binding assays. AAPS J. 2007:9(2):E260-7.

18. Eswar Kumar K, Ramesh A, yadav S. R and Satyanarayana S. Determination of gliclazide in rabbit serum by RP-HPLC. Acta Cienc Ind. 2007;33(3):273-78.
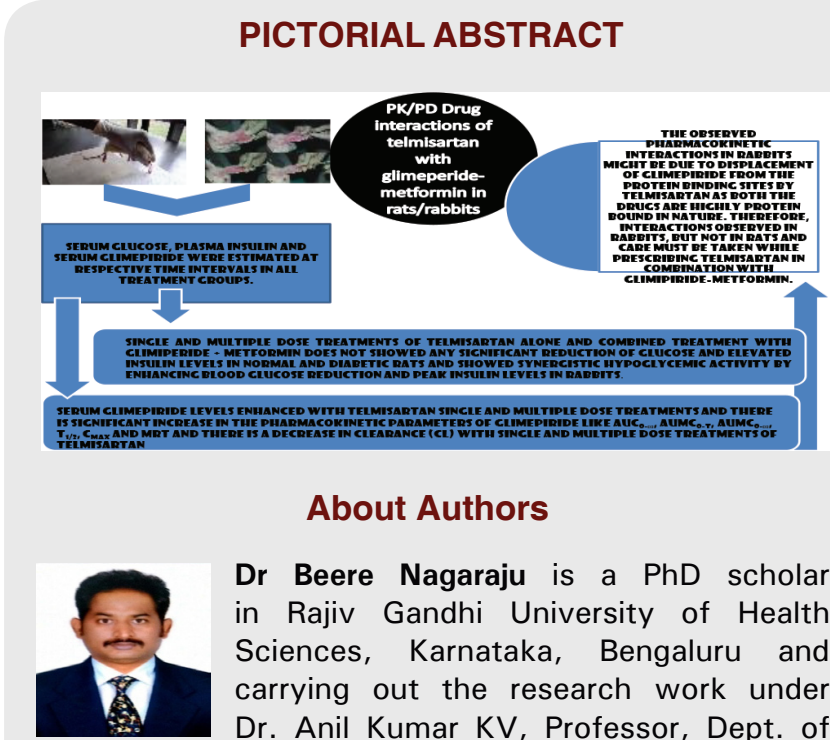

\section{About Authors}

Dr Beere Nagaraju is a PhD scholar in Rajiv Gandhi University of Health Sciences, Karnataka, Bengaluru and carrying out the research work under Dr. Anil Kumar KV, Professor, Dept. of Pharmacology, Visveswarapura Institute of Pharmaceutical Sciences (Mentor Institute: KIMS Hospital \& Research Centre), Bengaluru. He studied MPharm, PharmD and MBA and authored/ coauthored in more than 50 publications including case reports.

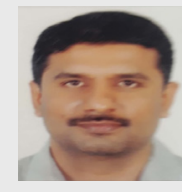

Dr. Anil Kumar KV is a Professor and PhD Guide in Dept. of Pharmacology of Visveswarapura Institute of Pharmaceutical Sciences (Mentor Institute: KIMS Hospital \& Research Centre), Bengaluru. He is having 21 yrs of teaching experience in the pharmacy. $\mathrm{He}$ has published 34 research articles in reputed national and international journals. Method for Simultaneous Estimation of Atorvastatin Calcium and Fenofibrate in Tablet Dosage Forms. Indian J Pharm Sci. 2008;70(2):263-5. doi: 10.4103/0250-474X.41473. PMID 20046730.

20. Gadge P, Gadge R, Paralkar N, Jain P, Tanna V. Effect of telmisartan on blood pressure in patients of type 2 diabetes with or without complications. Perspect Clin Res. 2018;9(4):155-60. doi: 10.4103/picr.PICR_93_17, PMID 30319944.

21. Wang $Y$, Qiao S, Han D, Rong X, Wang Y, Xue J, Yang J. Telmisartan Improves Insulin Resistance: A Meta-Analysis. Am J Ther. 2018;25(6):e642-51. doi: 10.1097/MJT.0000000000000733.

22. Wen J, Zeng M, Liu Z, Zhou H, Xu H, Huang M, Zhang W. The influence of telmisartan on metformin pharmacokinetics and pharmacodynamics. $J$ Pharmacol Sci. 2019;139(1):37-41. doi: 10.1016/j.jphs.2018.11.007, PMID 30538075.

23. Wienen W. 1Michael Entzeroth, 2Jacobus C. A. van Meel, Joachim Stangier Ulrich Busch. A Review on Telmisartan: A Novel, Long-Acting Angiotensin IIReceptor Antagonist. Cardiovasc Drug Rev. 2000;18(2):127-54.

\section{SUMMARY}

The objective of the present study is to evaluate the pharmacodynamic and pharmacokinetic interactions between telmisartan and glimepiride + metformin in single and multiple dose studies using normal and alloxan induced diabetic rats and normal rabbits. Blood samples were analyzed for blood glucose by GOD/POD method, insulin by ELISA, serum glimepiride levels by HPLC method at pre-determined time intervals. The single and multiple dose treatments of telmisartan alone and combined treatment with glimiperide + metformin does not showed any significant reduction of glucose and elevated insulin levels in normal and diabetic rats and showed synergistic hypoglycemic activity by enhancing blood glucose reduction and peak insulin levels in normal rabbits. The serum glimepiride levels were found to be enhanced with telmisartan single and multiple dose treatments. There is significant increase in the pharmacokinetic parameters of glimepiride like $\mathrm{AUC}_{0}$ $\infty, \mathrm{AUMC}_{0-\mathrm{t}}, \mathrm{AUMC}_{0-\infty}, \mathrm{t}_{1 / 2}, \mathrm{C}_{\max }$ and MRT and there is a decrease in clearance $(\mathrm{Cl})$ with single and multiple dose treatments of telmisartan. The interactions observed in rabbits, but not in rats. Hence, care must be taken by physicians while prescribing telmisartan with glimipiride-metformin combination.

Cite this article: Nagaraju B, Anilkumar KV. Influence of Telmisartan on Pharmacodynamic and Pharmacokinetic Properties of Glimepiride-metformin Combination using Rodent and Non-Rodent Models. Indian J of Pharmaceutical Education and Research. 2021;55(4):1060-5. 